\title{
Pentingnya Peningkatan Sumber Daya Manusia Bagi Masyarakat Melalui Pendidikan Tinggi Di Kabupaten Maybrat
}

\author{
Hermanto Suaib ${ }^{1}$, Salomina Gerewas ${ }^{2}$ \\ ${ }^{1,2}$ Fakultas Ilmu Sosial Dan Ilmu Politik, Universitas Muhammadiyah Sorong \\ Email: hermantosuaib@um-sorong.ac.id
}

\begin{abstract}
ABSTRAK
Tujuan dari penelitian ini adalah Untuk mengetahui bagaimana pentingnya Sumber Daya Manusia masyarakat Kabupaten melalui pendidikan tinggi di Kabupaten Maybrat. Metode dalam penelitian ini menggunakan metode kualitatif yang diperoleh secara langsung dari informan dilapangan yang menjadi objek penelitian berupa informasi yang relevan dengan masalah yang menjadi pertanyaan dalam penelitian ini. Hasil dari penelitian ini bahwa pemerintah agar lebih memperhatikan pelayanan sumber daya manusia melalui pendidikan di Kabupaten Maybrat dengan membuat suatu terobosan baru melalui pendidikan dengan memberikan satu keharusan khusus kepada kepala Dinas Pendidikan untuk lebih perperang aktif dalam menjawab setiap kebutuhan pendidikan. Kemudian membuat suatu aturan khusus kepada setiap pegawai atau guru yang tidak berada di tempat tugas selama seminggu, maka diberikan surat panggilan kepada yang bersangkutan agar segera ketempat tugas dan apabila lebih dari sebulan maka yang bersangkutan gajinya ditahan sampai yang bersangkutan datang ketempat tugas. Dengan peraturan seperti ini akan membuat pegawai atau guru itu lebih betah bekerja dengan baik dan bebar - benar dapat bekerja dengan baik sehingga pelayanannya pun akan dapat berjalan dengan baik.
\end{abstract}

Kata Kunci : Peningkatan SDM, Pendididikan Tinggi, Masyarakat

\begin{abstract}
The purpose of this study was to find out how important the human resources of the Regency community are through higher education in Maybrat Regency. The method in this study used a qualitative approach that was obtained directly from the informants in the field which became the object of research in the form of information relevant to the problem that was the question in this study. The results of this study that the government should pay more attention to human resource services through education in Maybrat Regency by making a breakthrough through education by providing a special requirement to the head of the Education Office for more active warriors in answering every educational need. Then make a special rule for each employee or teacher who is not in the assignment for a week, then a summons to the relevant person is given to place the job immediately and if more than a month the concerned salary is held until the interested person arrives at the assignment. With regulations like this, it will make the employee or teacher more comfortable working well and able to work well so that the service will run well.
\end{abstract}

Keywords : Increase in Human Resources, Higher Education, Society 


\section{Jurnal Noken volume 4 ( 2 ) Halaman : 173-187 2019}

\section{PENDAHULUAN}

Pendidikan adalah sebuah bentuk terhadap pelaksanaan pendidikan yang berlandaskan sosio - cultural, psikologis, ekonomis, dan politis yang ditujukan dalam mengembangkan watak dan karakter bangsa, sehingga berkepribadian nasional. Arti dari sebuah negara mengandung makna sebagai suatu masyarakat yang tersusun dalam mencapai sebuha tujuan utama yakni melindungi warga dari berbagai bahaya yang dating dari luar. Pada prosesnya pendidikan terselenggara dalam upaya menumbuhkan dan mengembangkan kepribadian sebuah bangsa demi memajukan kehidupan masyarakat pada berbagai sektor kehidupan, juga untuk mencapai tujuan nasional bangsa yang bersangkutan. (Anwar, 2016; Barnadid, 1991)

Perkembangan sebuah bangsa dilihat dari sejauh mana kemajuan dari Negara tersebut. Pada perkembangannya ilmu pengetahuan itu terkadang mengalami perubahan dan berkembang secara progresif. Hal ini bermakna bahwa pendidikan adalah sebuah kesatuan aktifitas yang berkaitan antara satu unsur dengan yang lainnya dalam mengupayakan terwujudnya tujuan pendidikan. Dalam sebuah sistem pendidikan, anak didik adalah warga Negara yang harus diberikan kesempatan menjadi peserta didik yang sesuai dengan persyaratan tertentu tanpa membedakan status sosial, ekonomi, agama, suku bangsa, dan sebagainya (Piet, 2000; Siagian, 2010)

Dilihat dari konsepnya, masyarakat merupaka sebuah kumpulan orang dari ragam kualitas diri mulai dari yang tidak berpendidikan sampai dengan yang berpendidikan tinggi. Disisi lain, dari aspek lingkungan pendidikan, masyarakat pada lingkungan pendidikan nonformal secara sengaja dan berencana kepada seluruh anggotanya diberikan pendidikan tetapi tidak dengan sistematis. Oleh karena itu, diharapkan pada setiap warga masyarakat mempunyai cita - cita serta aktif berkontribusi dalam membina pendidikan. Selain itu, tanpa dukungan dan partisipasi masyarakat, jangan diharapkan pendidikan dapat berkembang dan tumbuh sebagaimana yang diharapkan. Oleh kerana itu, sebagai salah satu lingkungan terjadinya kegiatan pendidikan, masyarakat mempunyai pengaruh yang sangat besar terhadap berlangsungnya segala aktifitas yang menyangkut masalah pendidikan. Apalagi bila dilihat dari materi yang digarap jelas kegiatan pendidikan 
baik yang termasuk jalur pendidikan sekolah maupun jalur pendidikan luar sekolah, berisihkan generasi muda yang akan meneruskan kehidupan masyarakat itu sendiri (Hasbullah, 2015).

Pendidikan yang tinggi merupakan salah satu tuntutan era globalisasi (Ali, 1987). Indonesia memiliki jumlah penduduk yang besar. Modal dasar yang berkualitas merupakan tujuan utama pembangunan manusia Indonesia seperti yang tertuang dalam pembukaan UUD 1945. Sumber Daya Manusia (SDM) yang berkualitas serta berpendidikan tinggi adalah upaya mempersiapkan SDM yang kompeten agar mampu bersaing dalam pasar kerja global. Meningkat Sumber manusia di Kabupaten maybrat, diperlukan untuk membangun Kabupaten Maybrat kedepan. Sumber Daya Manusia tidak terlepas dari kualitas pendidikan dan kesehatan. Peningkatan pendidikan di Kabupaten Maybrat diharapkan dapat meningkatkan akses dan pemerataan pelayanan pendidikan, peningkatan mutu dan relevansi pendidikan, serta penuntasan Wajib Belajar Pendidikan Dasar (Wajar Dikdas) Sembilan tahun. Selain itu, kedepan warga Kabupaten Maybrat yang melanjutkan pendidikan kejenjang yang lebih tinggi harus ditambah dan diperluas jangkauannya hingga masyarakat pedalaman. Untuk pendidikan tinggi yang merupakan jenjang kelanjutan pendidikan menengah, berdasarkan sensus nasional 2010, penduduk Provinsi Papua Barat usia 5 Tahun keatas yang tamat diploma (DI/DII/DIII) adalah sebesar 2,18 persen, tamat DIV/S1 sebesar 4,15 persen dan tamat $\mathrm{S} 2 / \mathrm{S} 3$ sebesar 0,25 persen.

Kabupaten Maybrat adalah salah satu Kabupaten Baru hasil pemekaran dari kabupaten induk Sorong Selatan. Kalau kita berbicara soal pendidikan khusus masyarakat Kabupaten Maybrat dikatan sebagian besar sudah memahami dan mengerti maksud dan makna pendidikan bagi itu sendiri. Namun, disayangkan bahwa sebagian besar masyarakat juga dilihat putus sekolah. Setelah di amati ternyata penyebabnya itu ada beberapa faktor diantaranya; faktor penunjang seperti sarana pendidikan (sekolah), orang tua yang tidak mampu membiaya anaknya ketingkat lanjut, jangkauan pendidikan yang begitu jauh dari masyarakat.

\section{METODE}

Jenis Penelitian yang digunakan adalah dengan menggunakan pendekatan Kualilitatif. Dimana Populasi dalam 
penelitian ini adalah beberapa warga masyarakat yang berdomisli di Kabupaten Maybrat. Pengambilan sampel yaitu dari beberapa populasi yang akan diteliti dilapangan untuk meminta keterangan antara lain : 1) Kepala Dinas Pendidikan Kabupaten Maybrat, 2) Sekretaris Dinas Pendidikan Kabupaten Maybrat, 3) Tokoh Pemuda dan OlahRaga Kabupaten Maybrat, 4) Tokoh Masyarakat di Kabupaten Maybrat, 5) Sebagian masyarakat di Kabupaten Maybrat. Adapun Pengumpulan data bersumber dari: 1) Observasi (Partisipasi / Non partisipasi), 2) Wawancara, 3) Dokumentasi.

\section{HASIL DAN PEMBAHASAN}

Bertempat di Kantor Dinas Pendidikan. Pemuda dan Olahraga yang diwawancarai adalah : Bapak Herman Kambu, S.Pd selaku Kepala Dinas Pendidikan Kabupaten Maybrat. "Sumber daya manusia di Kabupaten Maybrat, selalu bertambah dan meningkat di setiap tahun, karena berbicara tentang masalah pendidikan perguruan tinggi. Masyarakat Maybrat, mempunyai jiwa semangat yang semakin tinggi dalam menyekolahkan anak-anaknya demi kelangsungan kesejahteraan masyarakat dan keluarganya". Masyarakat Maybrat, sudah sedikit, berkembang dan maju serta mampu bersaing, dengan orang lain, dan Sumber Daya Manusia di Maybrat cukup banyak namun lapangan kerja yang belum ada, sehingga bias dapat mengakibat angka penganguran yang banyak pula.

Masyarakat Maybrat memiliki persatuan dalam membangun muttu Sumber Daya Manusia, karena mereka berpikir bahwa dengan ada modal Sumber Daya Manusia bisa dapat memberantas tingkat kemiskinan dan membawa suatu perubahan dan kesejahteraan hidup masyarakat Maybrat yang lebih baik lagi. Dengan adanya Sumber Daya Manusia inilah yang bisa mampu memimpin dan mengelolah hasil-hasil alam yang ada di Kabupaten Maybrat ini dengan kemampuan dan skil yang dimilikinya agar dapat membuat suatu perubahan bagi rakyat Maybrat ini lebih maju dan berkembang, dan benar-benar mengerti tentang arti pendidikan perguruan tinggi itu'.

Adapun Hasil wawancara dengan Bapak Herman Kambu adalah sebagai berikut : "Ketika berbicara tentang kondisi pendidikan dan perkembangan pendidikan dan peningkatan SDM di Kabupaten 


\section{Jurnal Noken volume 4 ( 2 ) Halaman : 173-187 2019}

Maybrat ini, selalu berjalan dengan baik dan lancer terkandung banyak sekali tantangan serta faktor - faktor yang banyak menghalangi serta menghambat suatu mutu pendidikan dan peningkatan SDM. Tetapi hal itu tidak menghambat kepada kesadaranmasyarakat serta anak - anak dan pemuda di Kabupaten Maybrat dalam mementingkan pendidikan demi masa depan mereka.

Pentingnya pendidikan dan peningkatan SDM di Kabupaten Maybrat benar - benar diharapkan oleh pemerintah dan masyarakat karena tampa pendidikan setiap manusia tidak berbuat apa - apa. Walaupun Kabupaten Maybrat merupakaan salah salah satu Kabupaten pemekaran baru di Provinsi Papua Barat yang di mekarkan dari Kaupaten induk Sorong Selatan, namun semuanya dalam pembangunan sarana dan prasarana umum seperti; peningkatan jalan lingkungan, terobasan jalan ke kampung - kampung, pembangunan rumah sakit, sekolah (PAUD, TK, SD, SMP, SMA dan SMK) semuanya sudah ada. Kalau berbicara mengenai pendidikan dan peningkatan SDM bagi masyarakat Maybrat, mereka sangat mengutamakan pendidikan. Karena dengan pendidikan orang akan lebih di pandang terhormat di Kabupaten Maybrat sehingga sekarang ini kita bisah lihat bahwa banyak pejabat - pejabat yang ada di Provinsi Papua Barat ini adalah berasal dari Kabupaten Maybrat. Masih banyak wilayah di Kabupaten Maybrat yang sangat jauh dari akses pemerintah daerah, tetapi pemerintah tetap memperhitungkan dan mejawab apa yang menjadi keluhan dan aspirasi mereka terutama pembangunan pendidikan dan kesehatan". (Maybrat 22 November 2017).

Ada beberapa masalah yang masih dipertimbangkan oleh pemerintah adalah sebagai berikut, 1) Kurangnya tenaga sumber daya guru, 2) Tenaga administrasi (TU) di sekolah masih kurang , 3) Perlengkapan alat - alat kantor (ATK) belum lengkap. Hal ini disebabkan oleh jangkauan wilayah yang jauh sehingga akses pendidikan sangat dibutuhkan oleh masyarakat. Perkembangan pendidikan peningkatan SDM Kabupaten Maybrat sangat diharapkan pemerintah, masyarakat dan orang tua, karena disetiap pembangunan wilayah dan Kabupaten kedepan nanti sangat diperlukan tenaga sumber daya manusia yang handal dan mampu bersaing dan memimpin negerinya sendiri. "Karena sifat pendidikan SD, SMP dan SMU di kampung tidak membutuhkan biaya yang mahal dan partisipasi dan 


\section{Jurnal Noken volume 4 ( 2 ) Halaman : 173-187 2019}

bimbingan orang tua pun sangat tinggi intuk mendorong anak itu agar bersekolah dengan baik. Dengan demikian ketika anak itu berpendidikan lanjut ke tingkat yang lebih tinggi maka, dengan sendirinya akan mendorong jiwa semangat yang semakin tinggi oleh orang tua maupun masyarakat dalam mendorong dan menopan anak dengan nasihat dan biaya. Kemudian juga ditambah dengan kemauan anak itu sendiri untuk berusaha, serta ingin merubah taraf hidup keluarganya yang mungkin juga bekerja sebagai petani.

Menuju masyarakat modern dengan gelar sarjana akan menjadi kebanggaan khusus bagi keluarga, orang tua dan masyarakat Kabupaten Maybrat. Oleh karena itu, dengan cara yang demikian masyarakat yang lain tidak bisa tinggal diam dengan keadaan sebelumnya, mereka selalu melihat, merasakan dan meniru agar bisah sama dengan orang lain juga. Mereka selalu berusaha dan bersaing agar mereka memiliki anak - anak bahagia dan sejahtera".

Apalagi pada zaman sekarang ini setiap anggota masyarakat dan pemuda Kabupaten Maybrat selalu menyadari akan peranan dan fungsi nilai pendidikan dan mutu SDM bagi masyarakat Kabupaten Maybrat. Oleh karena itu, sebagai salah satu lingkungan terjadinya kegiatan pendidikan masyarakat dan pemudah pengaruh yang sangat tinggi terhadap berlangsungnya segala aktifitas yang mengarah kepada pendidikan di Kabupaten Maybrat. Meningkatnya SDM di Kabupaten Maybrat sangat diharapkan pemerintah untuk membangun masyarakat yang maju kedepan. SDM Kabupaten Maybrat tidak tertlepas dari kualitas pendidikan dan kesehatan. Suatu peningkatan SDM dan mutu pendidikan selalu diharapkan agar dapat mengubah taraf hidup serta akses pemerataan dan pelayanan bagi masyarakat dengan baik. "Masyarakat Kabupaten Maybrat adalah masyarakat yang selalu hidup menjaling hubungan sosial dan cinta kasih yang tinggi.terkadangada yang membuat perpecahan antara tiga suku besar yaitu, Ayamaru, Aitinyo dan Aifat.mengenai masalah politik dan daerah kekuasaan, tetapi sanpai saat ini,semua cukup aman dan terkendali. karena disetiap masyarakat berarti pasti ada konflik yang terjadi pula dalam hal ini pemeritah tidak bisa tinggal diam saja,mereka selalu memikirkan persoalan dan masalah tersebut, semua ini menjadi tanggung jawab besar pemerintah daerah kabupaten maybrat". Hal ini bisa dilihat dari hasil wawancara dengan Bapak 
Joni Lantengi.S.Pd selaku Pengawas Sekolah.

Berpendapat bahwa di tiga belas kabupaten yang termasuk dalam propinsi papua barat, kabupaten maybrat masih terdapat mutu pendidikan terendah karena belum ada penjaminan muttu pendidikan yang baik. Ada beberapa faktor pendorong terjadinya pendidikan dikabupaten maybrat ?. 1) Pembangunan sarana dan pra sarana pendidikan sudah ada. 2) Pembangunan sarana dan prasarana kesehatann pun lengkap. 3) Partisipas masyarakat, orang tua, dan pemuda sangat tinggi. 5) Biaya pendidikan pun tidak terlalu mahal khusus sekolah dasar ( SD , SMP, SMA ). 6) Beasiswa selalu diberikan kepada anak - anak yang mampu. (Maybrat 23 November 2017).

Kelebihan masyarakat maybrat adalah ketika didalam satu anggota keluarga mereka memiliki beberapa anak yang memperoleh pendidikan, berarti mereka mampu membiayai sampai selesai berpendidikan.Apa bila ada yang tidak bisa lanjut pendidikan berarti akan mengakibatkan putus sekolah dan pengangguran yang banyak. Sifat yang dimiliki masyarakat ini adalah tidak kalah bersaing dengan orang lain dalam membangun sumberdaya manusia. Karena sifat pendidikan dikampung tidak membutukan biaya yang mahal dan partisipasi, bimbingan orang tua pun sangat tinggi untuk mendaorong annak itu agar sekolah dengan baik.

Dengan demikian ketika anak itu berpendidikan lanjut ketingkat yang tertinggi maka dengan sendirinya akan timbul semangat yang samakin tnggi oleh orang tua mau pun masyarakat dalam mendukunng dan menopang anak dengan nasehat dan biaya, dan juga kepada kemauan anak itu sendiri untuk mau berusaha serta ingin merubah taraf hidup kkeluarganya yang mungkin dulu bekerja sebagai petani menunjukan masyarakat yang modern atau makmur apabilah anakk tersebut berpendidikan lanjut sehingga memperoleh gelar serjana.makka akan membawah suatu kebanggaan bagi pemerintah, masyarakat, dan orang tua . Kabupaten maybrat dalam meningkatkkan muttu pendidikan dekemudian hari.

Oleh karena itu dengan cara demikian masyarakat yang lain tidakk bisa tinggal diam dengan keadaan yang sebelumnya, mereka selalu melihat merasakan dan menirunya agar bisa sama dengan orang lain juga mereka selalu berusaha dan bersaing agar mereka memiliki anakanakk yang memperoleh pendidikan dan 
mampu membuat orang tua bahagia dan sejatera. Apa lagi zaman sekarang ini setiap anggota masyarakat pemuda kabupaten maybrat selalu menyadari akan peranan dan fungsi nilai pendidikan dalam muttu pendidikan.Sumberdaya manusia bagi masyarakat kabupaten maybrat oleh karena itu sebagai salah satu lingkungan terjadinya kegiatan pendidikan masyarakat dan pemuda pengaruh yang sangat tinggi terhadap berlangsungnya segala akktifitas yang mengarah kependidikan dikabupaten maybrat. Meningkatkan sumberdaya mausia di kabupaten maybrat sangat diharapkan pemerintah untuk membangung maybrat yang maju kedepan. Sumberdaya manusia kabupaten maybrat tdk terlepas dari kulitas pendidikan dan kesehatan.Suatu peningkatan sumber daya manusia dan muttu pendidikan selalu diharapkan agar dapat mengubahtaraf hidup serta sksespemerataan dan pelayanan bagi masyarakat dengan baik.

\section{Pendidikan dan Pembangunan SDM dan Peran Pendidikan Dalam Pembangunan}

Pembangunan merupakan suatu proses yang berkisinambungan yang mencakup seluruh aspek kehidupan masyarakat, termasuk dalam aspek sosial, ekonomi, politik dan cultural dengan tujuan utama meningkatkan kesejahteraan warga bangsa secara keseluruhan. Dalam proses pembangunan tersebut peran pendidikan amatlah sangat strategis pendidikan mampu menciptakan SDM yang berkualitas, untuk itu peningkatan kualitas SDM mutlak harus dilakukan karena dengan kualitas SDM dapat memberikan multiplier efek terhadap opembangunan ekonomi. Walaupun peningkatan mutu pendidikan atau mutu SDM dilakukan jika tidak ada program yang jelas tentang mutu pendidikan dan program ekonomi yang jelas. Mengingat pentingnya peran pendidikan tersebut, maka investasi modal manusia melalui pendidikan di Negara berkembang sangat diperlukan walaupun investasi di bidang pendidikan jangka panjang secara makro, manfaat dari investasi ini baru dapat dirasakan puluhan Tahun.

\section{Pendidikan Sebagai Investasi Bagi Pembangunan Nasional}

Isu mengenai sumber daya manusia (human capital) sebagai input pembangunan ekonomi mencoba menjelaskan hubungan antara pendidikan dan pembangunan ekonomi untuk mencapai kesejahteraan, teori human capitalberpendapat bahwa pendidikan adalah sebagai investasi sumber daya 
manusia yang member banyak manfaat antara lain : 1) Diperoleh kondisi kerja yang lebih baik, 2) Efisiensi produksi, 3) Peningkatan kesejahteraan, 4) Tambahan pendapat seseorang apabila mampu menyelesaikan tingkat pendidikan yang lebih tinggi dibandingkan dengan pendapatan lulusan dibawahnya.

$$
\text { Pendidikan merupakan }
$$

investasi penting dalam menghadapi masa depan dunia secara global. Untuk itu, pendidikan harus dapat menyiapkan generasi muda di abat 21 yang unggul, berdaya saing tinggi dan mampu bekerja sama guna mencapai kemakmuran bagi setiap Negara dan dunia. Namun pembangunan tidak bisah akan timbuh dengan baik walaupun peningkatan mutu pendidikan atau mutu sumber daya manusia saat ini dalam proses perkembangan. Keterbatasan dana mengharuskan adanya prioritas dari berbagai pilihan gegiatan di bidang pendidikan, yang sesuai dengan jangka panjang akan mendorong laju pertumbuhan ekonomi. Investasi yang menguntungkan adalah investasi modal manusia untuk mempersiapkan kreatifitas dan jiwa kompetitif dalam masyarakat.

\section{Sitem Pendidikan dan Pembangunan Ekonomi}

Pemerintah memiliki peranan penting dalam meningkatkan kualitas dari sumber daya manusia (SDM) sehingga memiliki karakter, pengetahuan, values, attitudes dan skills yang dapat ditunjang melalui lembaga pendidikan, program pendidikan 9 Tahun, hal ini juga menjadi landasan dalam mensukseskan visi Indonesia dengan menggunakan dengan perekonomian yang baik. Adapun beberapa faktor yang menyebankan perlunya mengembangkan tingkat pendidikan di dalam usaha untuk membangun suatu perekonomian adalah : 1) Pendidikan yang lebih tinggi akan memperluas pengetahuan masyarakat dan mempertinggi rasionalitas pemikiran masyarakat. Hal ini memungkinkan masyarakat mengambila langka yang rasional dalam bertindak dan mengambil keputusan. 2) Pendidikan dapat memungkinkan agar masyarakat dapat mempelajari pengetahuan - pengetahuan teknis yang diperlukan untuk memimpin dan menjalankan perusahan - perusahan modern dan kegiatan - kegiatan modern lainnya. 3) Pengetahuan yang lebih baik yang diperoleh dari pendidikan menjadi perangsang untuk menciptakan 
pembaharuan - pembaharuan dalam bidang teknik, ekonomi dan dalam berbagai aspek bidang kehidupan masyarakat lainnya. 4) Sebagaimana benar bahwa SDM yang bermutu adalah yang mempunyai tingkat keahlian tinggi, juga yang tidak kurang benarnya adalah bahwa SDM tidak akan mencapai tingkah laku etnis dan moral yang tinggi berdasarkan keimanan yang teguh.

\section{Hakekat Pembangunan Manusia}

Pembangunan sumber daya manusia sebagi upaya untuk memberikan kesempatan seluas - luasnya kepada penduduk untuk terlibat aktif dalam proses pembangunan. Pada hakekatnya sumber daya manusia tidak hanya penting diperhatikan masalah keahlian sebagaimana yang telah umum dipahami dan diterima, tetapi juga penting diperhatiakan masalah keahlian sebagaimana benar bahwa SDM yang bermutu ialah yang mempunyai tingkat keahlian tinggi.

\section{Keputusan Berinvestasi (Analisis Biaya Manfaat)}

Telah diketahui bahwa peningkatan mutu modal manusia tidak dapat dilakukan dalam tempo yang singkat namun memerlukan waktu yang panjang. Investasi modal manusia sebenarnya sama dengan investasi faktor produksi lainnya. dalam hal ini juga di perhitungkan rate of return (manfaatnya) dari investasi pada modal manusia. Bila seorang akan melakukan investasi maka ia melakukan analisa biaya manfaat (cost benefit analisis). Biayanya adalah merupakan biaya yang dikeluarkan untuk bersekolah dan dan opportunity cost dari sekolah adalah penghasilan yang diterimanya. Sedangkan manfaat adalah penghasilan (ruturn) yang akan diterima dimasa depan setelah masa sekolah selesai. Diharapkan dari investasi ini manfaat yang dip[eroleh jauh lebih besar dari pada biayanya yang dikeluarkan saat ia berpendidikan. Maksud dari Pendidikan Tinggi adalah merupakan persoalan asasi bagi manusia. Manusia sebagai makluk yang dapat dididik dan harus dididik dan akan tumbuh menjadi manusia dewasa dengan proses pendidikan yang dialaminya. Sejak kelahirannya, manusia telah memiliki potensi dasar yang universal, berupa: 1) Kemampuan untuk membedakan yang baik dan yang buruk (moral identity); 2) Kemampuan dan kebebasan untuk mengembangkan diri sendiri sesuai dengan pembawaan dan cita - citanya (individual identity); 3) 


\section{Jurnal Noken volume 4 ( 2 ) Halaman : 173-187 2019}

Kemampuan untuk berhubungan dan kerja sama dengan orang lain (social identity); 4) Adanya ciri - ciri yang mampu yang membedakan dirinya dengan orang lain (individual differences).

Setiap anak mengalami proses pendidikan secara alamiah, yaitu yang ia dapatkan dalam pergaulan dengan orang lain pada umumnya dan pergaulan dengan kedua orang tuanya pada khususnya dalam lingkungan budaya yang mengelilinginya. Pendidikan seperti inilah yang menjadikan anak sebagai manusia dalam arti yang sesungguhnya. Cinta kasih orang tua dan ketergantungan serta kepercayaan anak pada mereka pada usia - usia mudah merupakan dasar kokoh yang memungkinkan timbulnya pergaulan mendidik. Dengan upaya pendidikan, potensi dasar universal anak akan tumbuh dan membentuk diri anak yang unik, sesuai dengan pembawaan, lingkungan budaya dan zamannya.

\section{Kendala Dalam Peningkatkan Sumber Daya Manusia di Kabupaten Maybrat}

Hasil wawancara Ibu Marlina Iek, SPd selaku Sekretaris Dinas pendidikan Kabupaten Maybrat. Terdapat beberapa kendala atau faktor penghambatan suatu pendidikan antara lain sebagai berikut : 1)
Disetiap sekolah (SD, SMP, SMA) masih kurang tenaga guru bidang studi. 2) Terdapat beberapa tenaga guru yang kurang disiplin dalam melaksanakan tugas dengan baik. 3) Jarak tempuh dari rumah ke sekolah sangat jauh. 4) Kondisi politik yang juga masih berpengaruh terhadap situasi pendidikan saat ini misalnya : a ) Pergantian Kepala Sekolah tiba-tiba. b) Perpindahan Ibu Kota Kabupaten dari Kumurkek ke Ayamaru yang tidak sesuai dengan aturan. c) Jabatan pegawai, CPNS, dan PNS diganti Tenaga Administrasi sekolah masih kurang, Perlengkapan alatalat kantor (ATK) belum lengkap. Hal-hal seperti ini bisa dapat berpengaruh besar terhadap lingkungan sosial masyarakat dan pola pelayanan pendidikan pun sangat terganggu.

Rendahnya kualitas SDM merupakan masalahmendasar yang dapat menghambat pembangunan dan perkembangan ekonomi nasional. Data statistic menunjukkan bahwa tenaga kerja Indonesia masih didominasi oleh mereka yang berpendidikan SD. Rendahnya pendidikan ini menurut Harsono (1997) merupakan penghambat dalam kemampuan mempergunakan teknologi modern untuk menghasilkan produk - produk yang 


\section{Jurnal Noken volume 4 ( 2 ) Halaman : 173-187 2019}

memiliki daya saing. Jika bagsa Indonesia ingin berkiprah dalam percaturan global, maka langkah pertama yang harus dilakukan adalah menata SDM: baik dari aspek intelektual, emosional, spiritual, kreatifitas, moral maupun tanggung jawabnya. "Dalam melaksanakan peningkatan sumber daya manusia bagi masyarakat melalui pendidikan tinggi di Kabupaten Maybrat, Faktor yang menjadi penghambat dalam pelaksanaan peningkatan sumber daya manusia antara lain dari pemerintah itu sendiri tetapi juga dari masyarakat sebagai penikmati pelayanan tersebut". (Maybrat 24 November 2017).

\section{Upaya yang dilakukan Pemerintah Dalam Peningkatan Sumber Daya Manusia bagi Masyarakat Melalui Pendidikan Tinggi di Kabupaten Maybrat}

Hasil wawancara Ibu. Welmina Naw, S.Sos selaku Tokoh Pemuda dan Olahraga Kabupaten Maybrat. Ada beberapa langkah dan upaya yang dilakukan oleh Pihak Pemerintah adalah sebagai berikut : 1) Sudah dibangun sarana dan prasarana pendidikan seperti gedung-gedung Sekolah baik dari tingkat terendah sampai Kepala Tingkat Pendidikan Tinggi (PAUD, TK, SD, SMP, SMU dan SMK) sudah ada lengkap. 2) Pembangunan sarana dan prasarana kesehatan pun lengkap dengan fasilitas-fasilitasnya dan tenaga kesehatannya. 3) Bea siswa selalu diberikan kepada anak-anak yang mampu. 4) Biaya pendidikan pun tidak terlalu mahal khsusus Sekolah Dasar (SD, SMP, SMU). 5) Pembangunan jaringan telepon dan wifi disetiap distrik-distrik sudah ada, sehingga dapat mempermudah masyarakat dan anak-anak dalam berkomunikasi jarak jauh dengan orang lain dan anak-anak sekolah untuk mencari tugas. 6) Pembangunan jalan utama dan terobosan jalan kekampung pun sudah ada, sehingga dapat mempermudah akses pelayanan pemerintah kepada masyarakat pun sangat lancar.

Disampaikan kepada pemerintah Kabupaten Maybrat, agar lebih memperhatikan pelayanan sumber daya manusia melalui pendidikan di Kabupaten Maybrat dengan membuat suatu terobosan baru melalui pendidikan dengan memberikan satu keharusan khusus kepada kepala Dinas Pendidikan untuk lebih perperang aktif dalam menjawab setiap kebutuhan pendidikan. Kemudian membuat suatu aturan khusus kepada setiap pegawai atau guru yang tidak berada 
di tempat tugas selama seminggu, maka diberikan surat panggilan kepada yang bersangkutan agar segera ketempat tugas dan apabila lebih dari sebulan maka yang bersangkutan gajinya ditahan sampai yang bersangkutan datang ketempat tugas baru di kasih gajinya. Dengan peraturan seperti ini akan membuat pegawai atau guru itu lebih betah bekerja dengan baik dan bebar - benar dapat bekerja dengan baik sehingga pelayanannya pun akan dapat berjalan dengan baik. Kemudian pemerintah kabupaten Maybrat juga harus memperhatikan sarana pendukun atau penunjang pendidikan seperti computer, listrik untuk menghidup computer dan juga akses jalan ketempat kerja yang kurang baik, perlatan belajar mengajar, karena semua ini merupakan penunjang bagi berlangsungnya suatu peningkatan sumber daya manusia melalui pendidikan. Sihingga dapat mewujudkan visi dan misi penyelenggaraan pemerintahan Kabupaten maybrat yaitu : 1) Mewujudkan Kabupaten Maybrat yang maju dalam berbagai aspek penyelengaraan pendidikan; 2) Membangun Kabupaten Maybrat untuk menuju kemandirian dalam pendidikan; 3) Mendorong penyelenggaraan pemerintahan Kabupaten Maybrat yang lebih memiliki keseimbangan dalam pendidikan.

\section{SIMPULAN}

Berdasarkan hasil penelitian ini dapat diberikan beberapa kesimpulan oleh peneliti adalah sebagai berikut : 1) Pentingnya peningkatan Sumber Daya Manusia bagi masyarakat melalui pendidikan tinggi di Kabupaten Maybrat.

2) Di Kabupaten Maybrat mutu sumber daya manusia selalu bertambah meningkat, namun masih juga terdapat beberapa hal yang menjadi hambatan dalam proses pendidikan diantaranya adalah : 3) Terdapat beberapa upaya dan langkah yang dilakukan oleh Pemerintah Kabupaten Maybrat adalah sebagai berikut : Telah dibangun sarana dan prasarana pendidikan seperti gedung-gedung sekolah baik dari tingkat (PAUD, TK, SD, SMP, SMA dan SMK) sudah ada dan lengkap dengan petugasnya, pembangunan sarana dan prasarana kesehatan misalnya (POSTU, Puskesmas dan Rumah Sakit Umum) sudah lengkap dengan petugas dan fasilitasnya yang lain, beasiswa dapat diberikan untuk siswa yang dikatakan mampu, biaya pendidikanpun tidak terlalu mahal bagi sekolah PAUD, TK, SD, SMP, dan SMU, pembangunan jaringan 
teleponpun sudah ada di setiap distrikdistrik sehingga dapat mempermudah arus komunikasi antara 2 arah yang saling berjuhan. Terutama kepada orang tua yang mempunyai anak-anak berpendidikan diluar kota. Masayrakat Maybrat hampir sudah sedikit makmur dan sejahtera dengan semua yang mereka milik dan rasakan semuanya ini karena adanya perhatian penuh dari pemerintah yang ingin mengsejahterakan masyarakat di Kabupaten Maybrat ini dengan baik pula.

\section{DAFTAR PUSTAKA}

Abdulsyani. Sosiologi Skematika. Teori. Dan Terapan. Bumi Aksara. Jakarta.

Anwar. Arsyad Ahmad. 2016. Pendidikan Anak Usia Dini. ALFABETA. Bandung.

Ali Hamdani.1987. Filsafat Pendidikan. Kembang. Yogyakarta.

Barnadid. Sutari Imam. 1991. Pengantar Ilmu Pendidikan Sistematis. FIPIKIP. Jakarta.

Basrowi. Suwardi. 2008. Memahami Penelitian Kualitatif. Rineka Cipta. Jakarta.

Barlian Ikbal. 2013. Manajemen Berbasis Sekolah Menuju Sekolah Berprestasi. Erlangga Group. Surabaya.
Coser. at all. 1983. introduction to Sociologi. Florida : Harcourt Brace Jovanovich

Dhumhur. 1979. Sejarah Pendidikan. Ilmu. Bandung

Elly M. Setiadi. H. Kama A. Kakam. Ridwan Effendi. 2007. Ilmu Sosial Budaya dan Dasar. KENCANA PRENADA MEDIA GROUP. Jakarta.

Hasbullah. 2015. Dasar - Dasar Ilmu Pendidikan. Raja Grafindo Persada. Jakarta.

Herabudin. 2015. Pengantar Sosiologi. Pustaka Setia. Bandung.

Hamalik Oemar. 2002. Psikologi Belajar dan Mengajar. Sinar Baru Algensindo. Bandung.

Muliansyah Abdurrahman Ways. Gerakan Sosial Studi NGO Lokal. Advokasi dan Pemberdayaan Masyaraka. Mata Padi Pressindo. Yogyakarta.

Mulyasa. E. 2009. Menjadi Kepala Sekolah Profesional. Remaja Rosdakarya Offest. Bandung.

Nasikun. 2011. Sistem Sosial Indonesia. RAJAGRAFINDO PERSADA. Jakarta.

Ndraha Taliziduhu. 2013. Pengantar Teori Pengembangan Sumber Daya Manusia. Rineka Cipta. Jakarta.

Nata Abuddin. 2003. Manajemen Pendidikan. Fajar Interpratama Offest. Jakarta. 


\section{Jurnal Noken volume 4 ( 2 ) Halaman : 173-187|| 2019}

Piet Sohertian A. 2000. Supervisi

Pendidikan Dalam Rangka

Pengembangan Sumber Daya

Manusia. Asda Mahasatya.

Jakarta.

Soejono Soekanto dan Budi Sulistyowati.

2012. Sosiologi Suatu

Pengantar. Rajagrafindo

Persada. Jakarta.

Sajogyo Pudjiwati Sajogyo. 2011. Sosiologi Pedesaan. GADJAH MADA UNIVERSITY PRESS. Yogyakarta.

Siagian. Sondang P. 2010. Manajemen Sumber Daya Manusia. Bumi Aksara. Jakarta.

Tirtarahadja Umar. Sula La. 2000. Pengantar Pendidikan. Rineka Cipta. Jakarta.

Usman Husain. 2008. Manajemen Teori Praktik dan Riset Pendidikan. Bumi Aksara. Jakarta. 